\title{
Cyberbullying among Normal and Attention Deficit Hyperactivity Disorder University Students (A Psychometric-Clinical Study)
}

\author{
Mohamed M. Abdelrazek ${ }^{1, *} \&$ Mahmoud M. Eltantawy ${ }^{2}$ \\ ${ }^{1}$ College of Education, King Khalid University, Saudi Arabia and Faculty of Specific Education, Ain Shams \\ University, Egypt \\ ${ }^{2}$ Faculty of Education, Ain Shams University, Egypt and College of Education, Al imam Mohammad Ibn Saud Islamic \\ University, Saudi Arabia \\ *Correspondence: Faculty of Education, Ain Shams University, Egypt and College of Education, Al imam \\ Mohammad Ibn Saud Islamic University, Saudi Arabia. E-mail: mmeltantawy@imamu.edu.sa
}

Received: January 24, 2020

Accepted: March 8, $2020 \quad$ Online Published: April 6, 2020

doi:10.5430/wje.v10n2p50

URL: https://doi.org/10.5430/wje.v10n2p50

\begin{abstract}
The present study aimed to investigate cyberbullying among normal and attention deficit hyperactivity disorder (ADHD) university students based on some variables. Its population comprised (1312) students at Saudi universities and disability centers and covered a sample of (148) normal and ADHD students encountering cyberbullying. Two clinical case studies were conducted. The study adopted the descriptive and analytical method, as well as the clinical approach. It utilized the cyberbullying scale, interview form, and Thematic Apperception Test. Results revealed the proliferation of some cyberbullying types among normal and ADHD university students. The cultural nature of the community affected the type of cyberbullying. Furthermore, there were differences in cyberbullying between normal and ADHD university students in favor of the ADHD students and between males and females, favoring the males. Such differences were caused by psychological and cultural variables.
\end{abstract}

Keywords: cyberbullying, ADHD, university students, psychometric/ clinical study

\section{Introduction}

The Internet has become an integral part of everyday life for carrying out many tasks. People use it to communicate with family members, friends, and others. The spread of smart devices helps people often interact and communicate via social media.

Vollink, Dehue, Guckin, and Jacobs (2016) describe the current generation as "the always-on generation" because of using technology to communicate. Despite the importance of social media, their use is risky. For example, users may be prone to cyberbullying, i.e. the deliberate use of the Internet or electronic communication tools to cause harm or disturbance to others intentionally and repeatedly (Akbulut \& Eristi, 2011; Ang \& Goh, 2010). According to Olweus (2012), cyberbullying is intended and frequent aggression via electronic devices between the bully and the victim. It takes many forms, including offensive messages, a thereat of rumors, disclosure of personal information, and publishing private images.

It has negative effects on the mental health of the victim and the bully, including anger, sadness, and depression. It results in many psychological problems to the victim, e.g. depression, anxiety, lower self-esteem, and alcohol abuse (Campbell, Slee, Spears, Butler, \& Kift, 2013; Kelly, Newton, Stapinski, Slade, Barrett, Conrod, \& Teesson, 2015; Salmivalli, Peets, \& Hodges, 2011). Mirsky and Omar (2015) argue that cyberbullying may cause suicide and psychological disorders to both bullies and victims.

Cyberbullying is not limited to the normal people, but it also includes those with ADHD that is known as a disorder marked by an ongoing pattern of inattention and/or hyperactivity-impulsivity (American Psychiatric Association, 2013). It prevails among those with ADHD because of the lack of social interaction. Consequently, they encounter problems of establishing relationships with others via social media. Kowalski, Morgan, Drake-Lavelle, and Allison (2016) revealed that university students with disabilities are at particular risk to cyberbullying victimization, including low self-esteem and high depression. Dawson, Wymbs, Evans and DuPaul (2019) argued that teens with ADHD use 
technology in similar ways as their normal peers, but they are at a unique risk of cyberbullying behaviors while using Facebook, such as poorer social skills and more internalizing symptoms. Moreover, Heiman, Shemesh, and Eden (2015) reported that students with ADHD feel greater social loneliness via the Internet. Reilly, Fogler, Selkie, and Augustyn (2016) conducted a study on a girl with ADHD who encountered cyberbullying because of posting photographs of herself in various stages of undress on Snapchat, which resulted in significant family problems.

Literature indicated the high rate of cyberbullying worldwide. For example, O'Moore (2014) reported that one out of four females and one out of six males were subject to cyberbullying. Vodafone Foundation (2015) surveyed (4,720) teens in (11) Arab states and found out that one out of five teens encountered cyberbullying. Kelly et al. (2015) reported that cyberbullying rated 10-15\% worldwide, while Li (2006) argued that cyberbullying victims rated (50\%). Smith, Mahdavi, Carvalho, Fisher, Russell, and Tippett (2008) reported the prevalence of cyberbullying outside school more than at school.

At the level of the Arab world, Fares (2013) concluded that cyberbullying among university students in Egypt was rated (58.9\%). In Lebanon, information theft, inappropriate photos, and unknown chatting rated 36.6\%, 18.9\%, and 62\% respectively (Center for Educational Research \& Development, 2015). In Bahrain, the Telecommunications Regulatory Authority $(2015)$ investigated $(1,637)$ participants and revealed that $(37.9 \%)$ were subject to cyberbullying. In Saudi Arabia, the Anti-Cyber Crime Unit (2017) received $(7,484)$ alarms by people who were cyberbullied via social media. In addition, the Anti-Extortion Unit received more than $(1,300)$ alarms of bullying. Statistics showed that $85 \%$ of bullying victims are aged 16: 30 yeas, mostly married women (58\%). Furthermore, (75\%) of cyberbullying takes place via social media. Most of the bullies (71\%) are aged 21:30 years, mostly for sexual purposes (i.e. $74 \%$ ) and financial ones (i.e. 14\%) (Arabian Business, 2018). Concerning patients with ADHD, Yen et al. (2014) reported that $(19.1 \%)$ and $(14.3 \%)$ participants reported that they were cyberbullying victims or perpetrators, respectively. Furthermore, cyberbullying victims had more depression and suicidality.

Traditional and cyberbullying differ in terms of the tools used and the electronic medium. The differences include (a) imbalance of power that is usually connected to the features of perpetrators and their relative physical and/or psychological power, but it is related to the technology used that allows hiding and lack of identity disclosure in cyberbullying; (b) unlike traditional bullying, cyberbullying takes place any time (Dooley, Pyżalski, \& Cross, 2009); (c) chasing the victim anytime and anywhere via messages or video files (Raskauskas \& Stoltz, 2007). Accordingly, the influence of the cyberbully increases (Holfeld, 2013). Kowalski and Limber (2013) reported that cyberbullying has a higher effect on mental health.

Cyberbullies and victims share a set of personal characteristics. Cyberbullies tend to arrogance, claim of fame, desire to control others, justifying violence towards others, failure to adhere to laws, and jealousy (Luker, and Curchack, 2017; Grigg, 2013). According to Campfield (2008) and Finkelhor, Ormrod, Turner, and Hamby (2005), the victim is characterized by tranquility, hypersensitivity, anxiety, fear, continuous insecurity, less tendency to violence, and passionate.

Cyberbullying takes many forms, including insult, defamation, joking, fraud, exclusion, harassment, trickery, hacking, and voting (Fares, 2013). Delfabbro et al. (2006) and Hillsberg and Spak (2006) illustrate that cyberbullying occurs by posting rumors to social media, harassment, as well as texting, e-mailing, and chatting for harassment.

Burton, Florell, and Wygant (2012) define some criteria for judging the behavior as cyberbullying. First, the action must be intended to cause harm. Second, there must be negative behaviors, rather than an isolated incident. Third, the bully-victim relationship has to be one with a power imbalance. Finally, it can arise from different technological means, such as chat rooms and social media.

Gleeson (2014) reports a direct correlation between technology use and cyberbullying and may turn the victims into cyberbullies. Bowler, Knobel, and Mattern (2015) argue that cyberbullying is the result of the advancement of communications, e.g. the Internet, mobile phones, and personal digital devices. Johnson (2016) suggests that cyberbullying prevails between young people. Moreover, there are higher correlation coefficients between mental disorders of anxiety and depression and cyberbullying between both the bullies and victims.

Because of its prevalence, especially at the university stage, and negative effects on the bully and the victim, the present study investigates cyberbullying among normal and ADHD university students and compares them based on some variables. The statement of the problem may be formulated in the following questions:

1. To what extent does each pattern of cyberbullying prevail among normal and ADHD University students?

2. Does cyberbullying (bully/ victim) differ among normal and ADHD University students? 
3. Does cyberbullying (bully/ victim) differ according to sex (male/ female) among normal university students?

4. What are the psychodynamics of the two clinical extreme cases (bully/ victim)?

\section{Method}

The authors adopted the descriptive and analytical method that investigates cyberbullying as well as the clinical approach. They conducted two extreme case studies (bully/ victim) to highlight their psychodynamics.

\section{Participants}

The population covered students at King Khalid University and Al-Imam Muhammad Ibn Saud Islamic University numbered $(1,312)$. The sample comprised (148) normal and ADHD students encountering cyberbullying. They were (115) normal students of which (74) were at King Khalid University and (41) at Al-Imam Muhammad Ibn Saud Islamic University; (83) males and (32) females. They were aged 18:23 years with a mean age of (20.25) years. They were intentionally selected of the population and tested the cyberbullying scale (bully/ victim). In addition, (33) students with ADHD aged (20:25) years with a mean age of (23.18) years and enrolled at the special needs centers of both universities and some external centers were selected. The students who surpassed the cut points on the scale were selected. The sample rated (11.28\%) of the population.

Two extreme cases were selected, i.e. a bully and a victim, based on their response to the cyberbullying scale. They were studied clinically by interviewing and applying the Thematic Apperception Test.

\section{Measures}

Cyberbullying scale (bully/ victim): The authors developed this scale to identify the bully and victim students in accordance with the population and culture electronically to be answered freely. They reviewed the relevant theoretical literature and frameworks to identify the concept and cultural aspects of cyberbullying. They also reviewed the scales of bullying (bully/ victim), in general, and cyberbullying, in particular, such as Alfareeh (2018) Emara (2017), Hussein (2016), Kowalski and Limber (2013), and Slonje and Smith (2008). They applied an open-ended questionnaire to (42) students at King Khalid University and Al-Imam Muhammad Ibn Saud Islamic University to identify the forms of cyberbullying that students may encounter. After that, they analyzed the content of responses, theoretical frameworks, literature, and scales. Then, they formulated the items in a simple manner. The first draft of the scale comprised (29) (yes/no) items. It was reviewed by a group of psychology and special education specialists to give their opinions about the items. Some items were modified in accordance. Later, the scale was applied to a sample of (10) students to identify the clarity and easiness of the items. After that, some words were edited to match Saudi culture. Exploratory factor analysis was conducted to define the domains of the scale prior to factor analysis. Moreover, content validity was calculated by calculating the correlation of each item to the total scale. It was found that all items are significant and rated (0.65-0.89). After that, factor analysis was conducted based on principal components because it helps define vectors, estimate the largest possible variance, and reduce the lowest number of uncorrelated variables. Kaiser criterion was used to estimate the extracted factor as an indicator for the completion of factor analysis and maintaining all components with eigenvalues above 1.0. Then, the orthogonal rotation of the scale was done. Factor analysis results in two items only (cyberbully- victim of cyberbullying). To define the psychometric characteristics of the scale, it was applied to a sample of (150) students. Reliability was calculated using the split-half and alpha coefficient, resulting in reliability coefficients of $(0.78$ and 0.82$)$, respectively. After that, validity was calculated by estimating face validity. Moreover, criterion-related validity was calculated by applying the bullying scale by Hussein (2016) as a criterion of the study. The correlation coefficient of the two scales was statistically significant and scored (0.62). Experimental validity was calculated by having an ascending order of the student scores and calculating the highest and lowest quarters and their differences. "T" value of the cyberbully and the victim was (22.78) and (17.33), respectively. It is statistically significant at the level of (0.01). Furthermore, the cut point was set to (18) scores and higher to judge the student as a bully and (22) scores and higher to judge the student as a victim of cyberbullying.

Interview form: The authors developed this form to collect data about the participant, as well as his/her family, social environment, and economic status. In the clinical part, it was used to identify the history of the participant and the reasons for cyberbullying behavior (bully/ victim), including the personal data, emergence of the problem, causes, problems, and family status. Finally, the thematic apperception test is reviewed to identify the dynamics clearly.

Thematic apperception test (TAT) (developed by Henry A. Murray, 1953 and translated by Khattab, 2017): Henry A. Murray developed the test consisting of 31 items of a person or many persons in ambiguous scenes. The respondents 
are asked to come up with an explanation for what is happening in the scene. The story expresses the personal dynamics because of the revealed emotions and desires. In other words, the respondent projects himself/herself into the story. The test reliability was calculated using the test-retest method. The reliability coefficients scored 0.80 based on a two-month interval and 0.50 on a ten-month interval. Many studies were conducted to calculate the validity of the test by comparing and discussing the results of the participants using other criteria to estimate the personality.

\section{Procedures}

They are, as follows: Reviewing relevant literature. Preparing the study tool, i.e. Cyberbullying scale, applying it after verifying the psychometric characteristics to the participants, applying the tools of the clinical study (interview formTAT test) to two extreme cases (a cyberbully and a victim), statistical analysis of the results, as well as concluding and discussing the results quantitatively and qualitatively using the clinical tools.

\section{Results}

To answer the first question, the percentage of each item of the cyberbullying scale was calculated to define the prevalence of cyberbullying, as shown in table (1).

Table 1. Percentages of Student Responses to the Cyberbullying Scale $(n=148)$

\begin{tabular}{|c|c|c|c|c|}
\hline \multirow{2}{*}{$\begin{array}{l}\text { Items } \\
\text { Cyberbully } \\
\end{array}$} & \multicolumn{2}{|c|}{$\begin{array}{c}\text { Normal students } \\
(\mathrm{N}=115)\end{array}$} & \multicolumn{2}{|c|}{$\begin{array}{l}\text { Students with ADHD } \\
(\mathrm{N}=33)\end{array}$} \\
\hline & Yes & No & Yes & No \\
\hline I quarrel with others via the Internet. & 38.3 & 61.7 & 87.9 & 12.1 \\
\hline I share others' secrets online unknowingly. & 16.5 & 83.5 & 72.7 & 27.3 \\
\hline I send offensive posts about others for defamation. & 10.4 & 89.6 & 63.6 & 36.4 \\
\hline I use social media to cause mental harm to others. & 24.3 & 75.7 & 93.9 & 6.1 \\
\hline I send threatening e-mails. & .9 & 99.1 & 72.7 & 27.3 \\
\hline I humiliate others online by spreading rumors. & 20.9 & 79.1 & 54.5 & 45.5 \\
\hline I mock others through e-mails. & 7.8 & 92.2 & 48.5 & 51.5 \\
\hline I harm others by posting their photos. & 30.4 & 69.6 & 54.5 & 45.5 \\
\hline I bully others by disseminating false news. & 3.5 & 96.5 & 90.9 & 9.1 \\
\hline I give up my real personality to hurt others online. & 98.3 & 1.7 & 81.8 & 18.2 \\
\hline I delude others using social media. & 96.5 & 3.5 & 84.8 & 15.2 \\
\hline I blackmail others by posting their porno photos to their pages. & .9 & 99.1 & 3.1 & 96.9 \\
\hline \multicolumn{5}{|l|}{ Victims } \\
\hline I was scammed by an online account. & 27.8 & 72.2 & 90.9 & 9.1 \\
\hline I received messages from fake accounts for defamation. & 13.9 & 86.1 & 72.7 & 27.3 \\
\hline I received offensive messages from anonymous accounts. & 99.1 & .9 & 84.8 & 15.2 \\
\hline I was lured by fake accounts into malicious links. & 3.5 & 96.5 & 63.6 & 36.4 \\
\hline My photos were hacked and posted unknowingly by fake accounts. & 3.5 & 96.5 & 81.8 & 18.2 \\
\hline I face threats to my safety by fake accounts. & 4.3 & 95.7 & 72.7 & 27.3 \\
\hline I am subject to various cyberattacks to obtain my personal data. & 2.6 & 97.4 & 63.6 & 36.4 \\
\hline I was forced into unbearable things by fake accounts. & 9.6 & 90.4 & 15.2 & 84.8 \\
\hline I was blackmailed financially by fake accounts. & 2.6 & 97.4 & 6.1 & 93.9 \\
\hline I was blackmailed sexually by fake accounts. & 13.0 & 87.0 & 12.1 & 87.9 \\
\hline Fake accounts posted pornographic images to my page deliberately. & 4.3 & 95.7 & 75.6 & 24.4 \\
\hline I was defamed by spreading rumors. & 7.0 & 93.0 & 63.6 & 36.4 \\
\hline Fake accounts posted my edited personal photos deliberately. & 4.3 & 95.7 & 9.1 & 90.9 \\
\hline After editing their content, my personal video clips were published. & 12.2 & 87.8 & 54.5 & 45.5 \\
\hline I suffered from psychological stress with fake accounts. & 90.4 & 9.6 & 81.8 & 18.2 \\
\hline Some online accounts made fun of me in public deliberately. & 99.1 & .9 & 90.9 & 9.1 \\
\hline Fake accounts frequently contacted me for bullying. & 93.9 & 6.1 & 33.3 & 66.7 \\
\hline
\end{tabular}

Table (1) shows different responses to the items regarding bullies. For the normal students, "I give up my real personality to hurt others online" was ranked first (98.3\%), "I delude others using social media" was ranked second 
(96.5\%), and "I quarrel with others via the Internet" was ranked third (38.3\%). For the students with ADHD, "I use social media to cause mental harm to others" was ranked first (93.9\%), "I bully others by disseminating false news" was ranked second (90.9\%), and "I quarrel with others via the Internet" was ranked third (87.9\%).

Concerning victims, responses show that normal students are subject to cyberbullying. "I received offensive messages from anonymous accounts" and "some online accounts made fun of me in public deliberately" were ranked first (99.1\%), while "I suffered from psychological stress by fake accounts" was ranked second (90.4\%). For the students with ADHD, "I was scammed by an online account" and "some online accounts made fun of me in public deliberately" were ranked first (90.9\%), while "I received offensive messages from anonymous accounts" was ranked second (84.8\%).

To answer the second question, the independent-samples t-test was utilized to define the differences between the normal and ADHD male university students only on the bullying scale, as shown in table (2).

Table 2. Arithmetic Mean, Standard Deviation, and (t) Values of the Difference between the Two Groups on the Cyber Bullying Scale $(\mathrm{N}=116)$

\begin{tabular}{llrrrrl}
\hline Groups & \multicolumn{2}{l}{ Normal students $(\mathrm{N}=83)$} & \multicolumn{2}{l}{ Students with ADHD $(\mathrm{N}=33)$} & \multirow{2}{*}{$(\mathrm{T})$ value } & Significance level \\
\cline { 2 - 5 } & $\mathrm{M}$ & S.D. & M. & S.D. & \\
\hline Cyberbullies & 14.3253 & 2.44505 & 29.8182 & 2.59151 & -30.270 & Significant at the level of 0.01 \\
Victims & 19.9157 & 2.69690 & 42.7273 & 4.15536 & 34.916 & Significant at the level of 0.01 \\
\hline
\end{tabular}

Table (2) illustrates statistically significant differences between the mean scores of normal and ADHD students in favor of the students with ADHD on the domains of the scale. (T) values scored (-30.270) and (34.916), respectively, which are statistically significant at the level (0.01).

To answer the third question, the independent-samples t-test was utilized to define the differences between the males and females on the bullying scale, as shown in table (3).

Table 3. Arithmetic Mean, Standard Deviation, and ( $\mathrm{t})$ Values of the Differences on the Cyberbullying Scale $(\mathrm{N}=$ 115)

\begin{tabular}{lcccccc}
\hline & \multicolumn{2}{l}{ Males $(\mathrm{N}=83)$} & \multicolumn{2}{c}{ Females $(\mathrm{N}=32)$} & \multirow{2}{*}{$(\mathrm{T})$ value } & Significance level \\
\cline { 2 - 5 } Groups & $\mathrm{M}$ & S.D. & $\mathrm{M}$ & $\mathrm{S}$.D. & & \\
\hline Cyberbullies & 14.36 & 1.77 & 13.56 & 0.80 & 2.44 & 0.01 \\
Victims & 19.86 & 3.39 & 18.46 & 1.90 & 2.19 & 0.03 \\
\hline
\end{tabular}

Table (3) shows statistically significant differences between the mean scores of the males and females in the "cyberbullies" and "victims" domains and the total score, in favor of the males. (T) Values scored (2.44) and (2.19), respectively, which are statistically significant at the level (0.05).

To answer the fourth question, two extreme clinical cases (bully/ victim) were selected based on the responses to the cyberbullying scale, interviewed, and tested TAT. They were asked to narrate a story of what goes on in the different scenes of the test. Then, their responses were discussed.

Case I: A cyberbully

It is a case of a son who grew up in a dysfunctional family. After a five-year marriage, the parents broke up and married to other couples. The son moved to the house of his maternal grandfather who used to mollycoddle him, although the father was very tough and the mother was disinterested to meet the desires of her new husband. Consequently, he became a low achiever. He was hard-bodied. He tended to show strength, pride himself on risk confrontation and others' fear of him. Moreover, he preferred horror and violence movies. However, he suffered from isolation and a lack of friends.

His responses to the TAT card showed loneliness, confrontation, and show-off. They illustrated the family problems and feelings of parental neglect. He tended to violence, aggression, self-esteem by bullying others. Accordingly, he became a cyberbully.

Case II: A victim

It is a case of a single male student born after five years of marriage. The mother showed excessive protection, mollycoddling, and interfering in all affairs. Parental disagreements raised, and the father rejected and dealt him 
harshly to achieve balance. Consequently, the student became introvert and turned to cyberspace to compensate for his isolation. Moreover, he had neither hobbies nor friends.

Applying TAT cards showed extreme shyness, low self-esteem, and parental isolation. The father handled him aggressively, unlike the mother who tended to mollycoddle. This imbalanced treatment caused emotional conflict and inability to fulfill his role. Furthermore, he had no friends. He had feelings of fear, weakness, insecurity, selfinjury, depression, and escapism.

\section{Discussion}

The present study investigated cyberbullying among normal and ADHD university students. Results revealed that the prevalence of cyberbullying rated (11.28\%). In addition, some types of cyberbullying were higher among both normal and ADHD university students because of the cultural nature, customs, traditions, and laws of the Saudi community that have a significant impact. For example, "I give up my real personality to hurt others online" was rated $(98.3 \%)$ and $(81.8 \%)$, respectively. Its rate was low among the students with ADHD due to impulsiveness, indifference to the customs and traditions, and tendency to breach laws. Sexual blackmail was ranked last and rated $(0.9 \%)$ and $(3.1 \%)$, respectively because of the cultural nature of the community. The students encountered both types of cyberbullying: Cyberbully and victim.

There were differences between the groups of normal and ADHD students in cyberbullying (bully/ victim) in favor of the ADHD students because of the direct effect of ADHD on social interaction and the difficulty of making and maintaining friendships. Therefore, they fail to interact via social media, become aggressive and encounter cyberbullying (bully/victim). Dawson et al. (2019) reported how adolescents with ADHD suffer from aggressive cyberbullying behaviors while using Facebook concerning difficult connection and social interaction with others. Heiman et al. (2015) revealed that students with ADHD feel higher social loneliness online.

Furthermore, results revealed differences between the males and the females in cyberbullying (bully/ victim) or the total score in favor of the males due to the sex differences and culture that gives more freedom to the males. The males are more aggressive and tend to risk (Archer \& Coyne, 2005). These findings agreed with the results of Heiman and Olenik-Shemesh (2013), Lapidot- Lefler and Dolev- Cohen (2015), and Robson and Witenberg (2013) that there are differences between the males and females in bullying in favor of the males. The differences in the domain of victim favoring the males are caused by the turn-taking between the bully and the victim as a reaction to bullying to others. The findings differed from the results of Brown, Demaray, and Secord (2014) and Connell, Schell- Busey, Pearce, and Negro (2013) concluding differences in cyberbullying in favor of the females. Therefore, social media should be used cautiously to reduce dangers, including social isolation and cyberbullying.

The findings of Robson and Witenberg (2013) illustrated the impact of age on cyberbullying practice, in favor of the old, suggesting a high percentage of cyberbullying among the participants as university students. The males surpassed the females in cyberbullying. This finding matches Heiman and Olenik- Shemesh (2013), concluding that the females were victims more than the males because of the nature of the Saudi community that does not give the woman similar freedom in practicing the different activities. Accordingly, she uses social media and becomes obsessed with different websites.

The findings of the clinical study matched those of Akiba (2004), reporting that the bullies and victims suffer from familial problems, such as disintegration, mistreatment, emotional insecurity of the victim. They agreed with Monks, Smith, Naylor, and Barter (2009) that both bullies and victims lack tranquility and psychological security and have high rates of anxiety. They also matched the results of Terrazo, Garcia, Babarro, and Arias (2014), showing that the bullies are aggressive and hyperactive. On the contrary, the victims are characterized by shyness, social withdrawal, and low self-concept. They agreed with the results of Perkins and Berrena (2002) revealing that the victims suffer from anxiety and psychosomatic disorders, and those of Cranham and Carroll (2003), showing that the personal characteristics of the victims include emotional loneliness and lack of social interaction. The results agreed with Huang and Chou (2010) reporting that the victims show high rates of fear and anxiety, but the bullies show psychological security. Concerning the family role in bullying, the findings agreed with Mazefsky and Farrell (2005) that permissive or tough parenting increases cyberbullying.

The study recommends helping the victims of cyberbullying get rid of the negative implications of the shock, raise awareness, and establish intervention programs. It also recommends investigating cyberbullying among various age groups, as well as the psychological and cultural variables related to cyberbullying in the community. It recommends drawing profiles of the bullies and victims and investigating it among the disabled at the university. 


\section{Conclusion}

The study investigated cyberbullying among normal and ADHD university students in a different cultural environment controlled by a set of traditions and customs. Results revealed the prevalence of cyberbullying among normal university students and more prevalence among students with ADHD due to impulsiveness. The common patterns of cyberbullying among the students differed in terms of form and prevalence due to the culture of the population. For example, participants reported an increase in giving up real personalities to hurt others online and low sexual blackmail. There were differences in cyberbullying (victim and bully) between normal and ADHD university students (in favor of the ADHD students because of indifference to the prevailing laws and tendency to breach laws. They suffer impulsiveness, problems of social interaction, and difficulty in perceiving the implications of their actions. There were differences in cyberbullying between males and females, favoring the males because of the culture that allows more freedom, activities, and tasks to the males. The clinical study revealed many psychological, social, and social dynamics, as well as abnormal parental treatment that cause cyberbullying (victim and bully), as shown in divorce, cruelty, isolation, mollycoddle, and lack of friends in the two case studies.

\section{References}

Akbulut, Y., \& Eristi, B. (2011). Cyberbullying and victimisation among Turkish university students. Australasian Journal of Educational Technology, 27(7), 1155-1170.

Akiba, M. (2004). Nature and correlates of Ijime-bullying in Japanese middle school. International Journal of Education Research, 41(3), 216-236. https://doi.org/10.1016/j.ijer.2005.07.002

Alfareeh, S. (2018). Cyberbullying in public schools from the perspective of teacher-students at Kuwait University. The Educational Journal- Kuwait, 32(126), 15-58.

American Psychiatric Association (2013). Diagnostic and statistical manual of mental disorders (5th ed.). American Psychiatric Pub DSM-5.

Ang, R. P., \& Goh, D. H. (2010). Cyberbullying among adolescents: The role of affective and cognitive empathy and gender. Child Psychiatry Hum Dev, 41, 387-397. https://doi.org/10.1007/s10578-010-0176-3.

Arabian Business (2018). What to do to avoid bullying in Saudi Arabia. Retrieved from https://arabic.arabianbusiness.com/content/331848

Archer, J., \& Coyne, S. (2005). An integrated review of indirect, relational, and social aggression. Personality and social psychology review, 9(3), 212-230. https://doi.org/10.1207/s15327957pspr0903_2

Bowler, L., Knobel, C., \& Mattern, E. (2015). From cyberbullying to well-being: A narrative-based participatory approach to values-oriented design for social media. Journal of the Association for Information Science and Technology, 66(6), 1274-1293. https://doi.org/10.1002/asi.23270

Brown, C., Demaray, M., \& Secord, S. (2014). Cyber victimization in middle school and relations to social emotional outcomes. Computers in Human Behavior, 35, 12-21. https://doi.org/10.1016/j.chb.2014.02.014.

Burton, K., Florell, D., \& Wygant, D. (2012). The role of peer attachment and normative beliefs about aggression on bullying and cyberbullying. Psychology in the Schools, 50, 103-115. https://doi.org/10.1002/pits.21663

Campbell, M., Slee, P., Spears, B., Butler, D., \& Kift, S. (2013). Do cyberbullies suffer too? Cyberbullies' perceptions of the harm they cause to others and to their own mental health. School Psychology International, 34(6), 613-629.

Campfield, D. (2008). Cyber bullying and victimization: Psychosocial characteristics of bullies, victims, and bully/victims (Ph.D. dissertation). The University of Montana, Missoula.

Center for Educational Research \& Development (2015). Child safety on the Internet: A national survey of the effect of the Internet on children in Lebanon. Republic of Lebanon: Ministry of Education.

Connell, N., Schell-Busey, N., Pearce, A., \& Negro, P. (2013). Badgrlz? Exploring sex differences in cyberbullying behaviors. Youth Violence and Juvenile Justice, 12(3), 209-228. https://doi.org/10.1177/1541204013503889.

Cranham, J., \& Carroll, A. (2003). Dynamics within the bully/victim paradigm: A qualitative analysis. Educational Psychology in Practice, 19(2), 113-132. https://doi.org/10.1080/02667360303235.

Dawson, A., Wymbs, B., Evans, S., \& DuPaul, G. (2019). Exploring how adolescents with ADHD use and interact with technology. Journal of Adolescence, 71, 119-137. https://doi.org/10.1016/j.adolescence.2019.01.004 
Delfabbro, P., Winefield, T., Trainor, S., Dollard, M., Anderson, S., Metzer, J., \& Hammarstrom, A. (2006). Peer and teacher bullying/victimization of South Australian secondary school students: Prevalence and psychosocial profiles. British Journal of Educational Psychology, 76(1), 71-90. https://doi.org/10.1348/000709904X24645

Dooley, J. J., Pyżalski, J., \& Cross, D. (2009). Cyberbullying versus face-to-face bullying: A theoretical and conceptual review. Journal of Psychology, 217(4), 182-188. https://doi.org/10.1027/0044-3409.217.4.182

Emara, I. (2017). Traditional and cyberbullying among pre-university studies. Journal of Arabic Studies in Education \& Psychology, 86, 513-548.

Fares, N. (2013). Effectiveness of self-paced e-learning in developing the concepts of the protection against cyberbullying and self-regulation among the students of the Faculty of Specific Education, South Valley University. Journal of the Faculty of Education in Assiut, 29(2), 232-279.

Finkelhor, D., Ormrod, R., Turner, H., \& Hamby, S. (2005). The victimization of children and youth: A comprehensive, national survey. Child maltreatment, 10(1), 5-25. https://doi.org/10.1177/1077559504271287

Gleeson, H. (2014). The prevalence and impact of bullying linked to social media on the mental health and suicidal behavior among young people. UK: HSE National Office for Suicide Prevention.

Grigg, D. (2013). Definitional concepts of bullying and aggression from traditional platforms to cyber-repertoire (Ph.D. dissertation). Goldsmiths, University of London.

Heiman, T., Shemesh, D., \& Eden, S. (2015). Cyberbullying involvement among students with ADHD: Relation to loneliness, self-efficacy and social support. European Journal of Special Needs Education, 30(1), 15-29. https://doi.org/10.1080/08856257.2014.943562

Heiman, T., \& Olenik-Shemesh, D. (2013). Cyberbullying experience and gender differences among adolescents in different educational settings. Journal of Learning Disabilities 48(2) 146-155. https://doi.org/10.1177/0022219413492855

Hillsberg, C., \& Spak, H. (2006). Young adult literature as the centerpiece of an anti-bullying program in middle school. Middle School Journal, 38(2), 23-28.

Holfeld, B. (2013). A social ecological approach to cyber bullying (Ph.D. dissertation). The University of North Dakota, North Dakota.

Huang, Y., \& Chou, C. (2010). An analysis of multiple factors of cyber bullying among Junior high School students in Taiwan. Computers in Human Behavior, 26(6), 1581-1590. https://doi.org/10.1016/j.chb.2010.06.005.

Hussein, R. (2016). Factorial structure of the scale of cyberbullying as perceived by the victim among adolescents. Arab Journal for Studies and Research of Educational and Human Sciences, 4, 40-85.

Johnson, K. (2016). Oh, what a tangled web we weave: cyberbullying, anxiety, depression, and loneliness (MA. thesis). University of Mississippi, Oxford.

Kelly, E., Newton, N., Stapinski, L., Slade T., Barrett E., Conrod P., \& Teesson, M. (2015). Suicidality, internalizing problems and externalizing problems among adolescent bullies, victims and bully victims. Preventive Medicine, 73, 100-105. https://doi.org/10.1016/j.ypmed.2015.01.020

Kowalski, R., \& Limber, S. (2013). Psychological, physical, and academic correlates of cyberbullying and traditional bullying. Journal of Adolescent Health, 53(1), 13-20. https://doi.org/10.1016/j.jadohealth.2012.09.018

Kowalski, R., Morgan, C., Drake-Lavelle, K., \& Allison, B. (2016). Cyberbullying among college students with disabilities. Computers in Human Behavior, 57, 416-427. https://doi.org/10.1016/j.chb.2015.12.044

Lapidot-Lefler, N., \& Dolev-Cohen, M. (2015). Comparing cyberbullying and school bullying among school students: prevalence, gender, and grade level differences. Social Psychology of Education, 18(1), 1-16. https://doi.org/10.1007/s11218-014-9280-8

Li, Q. (2006). Cyberbullying in schools: A research of gender differences. School Psychology International, 27(2), 157-170. https://doi.org/10.1177/0143034306064547

Luker, J., \& Curchack, B. (2017). International perceptions of cyberbullying within higher education. Adult Learning, 28(4), 144-156. https://doi.org/10.1177/1045159517719337 
Mazefsky, C., \& Farrell, A. (2005). The role of witnessing violence, peer provocation, family support, and parenting practices in the aggressive behavior of rural adolescents. Journal of Child and Family Studies, 14(1), 71-85. https://doi.org/10.1007/s10826-005-1115-y.

Mirsky, E., \& Omar, H. (2015). Cyberbullying in adolescents: The prevalence of mental disorders and suicidal behavior. Journal of Child and Adolescent Health, 8(1), 37-39.

Monks, C., Smith, P., Naylor, P., \& Barter, C. (2009). Bullying in different contexts: Commonalities, differences and the role of theory. Aggression and Violent Behavior, 14(2), 146-156. https://doi.org/10.1016/j.avb.2009.01.004.

Olweus, D. (2012). Cyberbullying: An overrated phenomenon? European Journal of Developmental Psychology, 9(5), 520-538. https://doi.org/10.1080/17405629.2012.682358

O'Moore, M. (2014). Understanding cyberbullying: A guide for parents and teachers. Ireland: Veritas.

Perkins, D., \& Berrena, E. (2002). Bullying what parent can do about it. Agricultural research and cooperative extension. The Pennsylvania State University. College of Agricultural Science. Retrieved from http://kidsbridgecenter.org/wp-content/uploads/2012/08/Bullying_WhatParentsCanDoAboutIt.pdf

Raskauskas, J., \& Stoltz, A. (2007). Involvement in traditional and electronic bullying among adolescents. Developmental Psychology, 43(3), 564-575. https://doi.org/10.1037/0012-1649.43.3.564.

Reilly, M., Fogler, J., Selkie, E., \& Augustyn, M. (2016). Attention-deficit/hyperactivity disorder-related impulsivity and cyberbullying in social media. Journal of Developmental \& Behavioral Pediatrics, 37(6), 511-513. https://doi.org/10.1097/DBP.0000000000000308.

Robson, C., \& Witenberg, R. (2013). The influence of moral disengagement, morally based self-esteem, age, and gender on traditional bullying and cyberbullying. Journal of School Violence, 12(2), 211-231. https://doi.org/10.1080/15388220.2012.762921

Salmivalli, C., Peets, K., \& Hodges, E. (2011). Bullying. In: P. Smith, \& C. Hart, the Wiley- Blackwell Handbook of Childhood Social Development (2nd ed.) (pp: 510-528). New Jersey: Blackwell Publishing Ltd.

Slonje, R., \& Smith, P. (2008). Cyberbullying: Another main type of bullying? Scandinavian Journal of Psychology, 49, 147-154. https://doi.org/10.1111/j.1467-9450.2007.00611.x

Smith, P. K., Mahdavi, J., Carvalho, M., Fisher, S., Russell, S., \& Tippett, N. (2008). Cyberbullying: Its nature and impact in secondary school pupils. Journal of child psychology and psychiatry, 49(4), 376-385. https://doi.org/10.1111/j.1469-7610.2007.01846.x

Telecommunications Regulatory Authority (2015). Studying safety on the Internet. Bahrain: Telecommunications Regulatory Authority.

Terrazo, M., Garcia, S., Babarro, J., \& Arias, R. (2011). Social characteristics in bullying typology: Digging deeper into description of bully-Victim. Procedia-Social and Behavioral Sciences, 29, 869-879. https://doi.org/10.1016/j.sbspro.2011.11.316

Vodafone Foundation (2015). Vodafone global survey on cyberbullying. Retrieved from https://www.vodafone.com/content/dam/vodafone-images/parents/assets-2016/pdf/cyberbullying_survey.pdf

Vollink, T., Dehue, F., Guckin, C., \& Jacobs, N. (2016). An introduction in cyberbullying research. In T. Vollink, F. Dehue, \& C. Guckin (Eds.), Cyberbullying from theory to intervention. NY: Routledge.

Yen, C., Chou, W., Liu, T., Ko, C., Yang, P., \& Hu, H. (2014). Cyberbullying among male adolescents with attention-deficit/hyperactivity disorder: Prevalence, correlates, and association with poor mental health status. Research in Developmental Disabilities, 35(12), 3543-3553. https://doi.org/10.1016/j.ridd.2014.08.035 